\title{
The Research of Chinese Civil Aviation Market under the Environment of Electronic Commerce
}

\author{
Dong Lu* \\ Shanghai Civil Avation College, Shanghai 200232, China. \\ 13901785925@126.com
}

\begin{abstract}
The increasing popularity of the Internet and the wide application of information technology have promoted the rapid development of China's e-commerce market. As a concentrated reflection of the network economy in the market transaction level, e-commerce has always been the focus of academic circles. In order to study the Chinese civil aviation market under the e-commerce environment, this paper uses the B2C civil aviation ticket market data to test the Bacchus -frictionless trading hypothesis. The research results show that there is still a significant price difference in the same commodity in the e-commerce environment, that is, the hypothesis Failure to effectively explain the reality.
\end{abstract}

Keywords: Civil aviation market; electronic commerce; inspection method introduction.

\section{Introduction}

The increasing popularity of the Internet and the wide application of information technology have laid a solid foundation for the development of China's e-commerce market and have opened up broad prospects. Data show that by the end of 2015, the scale of Internet users in China has reached 688 million, the Internet popularity rate reached $50.3 \%$, of which network shopping users have reached 413 million, accounting for more than $60 \%$ of all Internet users. At the same time, the data of the Ministry of Commerce showed that the retail trade of our country reached 3 trillion and 880 billion Yuan in 2015, accounting for $10.8 \%$ of the total retail sales of social consumer goods. Like any new thing, e-commerce is a network. The concentrated expression of the economy in the market transaction level has aroused widespread concern in the academic circles. Stigler (STIGLERGJ) has repeatedly pointed out that market friction will be reduced as information is easier to be obtained by consumers, accompanied by a substantial increase in the effectiveness of market transactions. This pioneering achievement has become the beginning of the discussion of the role of information in the economy. In the late 1980 s, the extensive application of electronic commerce in market transactions set off another academic climax in the academic circles on the role of information in market transactions. [1]

On the other hand, from the growth rate of the civil aviation transport market, the total transport turnover, passenger transport volume and cargo transport volume of China Civil Aviation in the 10 years from 2000 to 2010 increased by $18.2 \%$ respectively, $17.9 \%$ and $16.2 \%$ according to the statistical yearbook of 2016 (the average annual growth rate of GDP calculated by the data was $16.36 \%$ ), and the comparison data showed that the people of civil aviation were of the annual growth rate of $16.36 \%$. The aviation transportation industry is playing a more and more important role in the macro-economic operation at the speed that it is obviously higher than that of GDP. As the growth of the civil aviation industry is increasing more and more in the original system, the performance evaluation of the existing reform measures has been highly concerned by the government decisionmaking level, the civil aviation ticket pricing and other issues have been highly concerned by the public. [2] The academic circle has made the Chinese civil aviation market under the e-business environment. Research has also gradually heated up. 


\section{Discussion on the Standard of Empirical Test}

\subsection{Research Object and Hypothesis}

Considering the market maturity and the nature of the product, this study takes the $\mathrm{B} 2 \mathrm{C}$ air ticket market in China as the research object, and applies the hypothesis test standard proposed above to the market. The basic hypothesis of this study can be obtained: for the same booking principle, the same airline is recommended by different competitive online ticket agents. The price of the same flight should be the same or there is no significant difference. The above basic assumptions need to be explained as follows: first, the booking principles mentioned above refer to the general procedures and procedures for passenger booking. The two is the choice of the same product in the inspection standard. Under the principle of clear booking, there will be differences in the definition of the same product: one may be to consider the airline tickets on the same route as the same product for the different online agents; the other is to consider the same kind of airline ticket as the same kind of airline. The product is studied. [3] This study believes that the study of the same route as the same product is difficult to separate the influence of airline competition on air fare, that is, the results of the study are not the result of the competition between online agents, but the same product can separate the influence of the airline competition as much as possible. [4].

\subsection{Sample and Date}

The data of this study come from the online airline Agency (OTA). The study refers to the "thirtyfifth China Internet network development statistics report" issued by the China Internet Information Center (China Internet Information Center), and selects the 4 top ticket sales agencies (hereinafter referred to as OTA1, OTA2, OTA3, and OTA4) as the data sources. One of the characteristics of online airline ticket sales is that airline tickets on the same flight may change in a very short time. Therefore, in order to ensure the reliability of the research data of the ticket price, and to reduce the cost of consumer search for e-commerce application, the competition between the suppliers and the suppliers is intensifying in a wider range, and the inconsistency of the efficiency of 95 students to reduce the efficiency of the market transaction is compared with the barriers to commodity information entry. All the data should be in the same way. The collection is completed at a time point or a very small interval. This research adopts the following data acquisition method to meet the above requirements: the price data of the same flight for second days in the same period of time are captured at the same time point every day. [5] In addition, taking into account the diversity of different types of airfares, this study only collects the comparability of airfares between institutions (excluding business packages). Specifically, the study selected 8 flights, 10 airlines, 30 flights, and 5 classes of airfares as a collection object, and collected data from February 25, 2016 to March 25, 2016 for a month. Considering that most flights are not characteristic of continuous daily flights, the study removes flights that do not exist on the day's price data. Descriptive statistics of ticket price data collected by the Institute.

Table 1. The descriptive statistics of air ticket price data

\begin{tabular}{|c|c|c|c|c|c|}
\hline & number & average price / yuan & standard deviation & maximum value & minimum value \\
\hline first class & 3200 & 3698.22 & 1250.62 & 7288 & 982 \\
\hline economy class & 3115 & 752.19 & 284.35 & 2235 & 185 \\
\hline
\end{tabular}

\section{Experiment and Result Analysis}

The purpose of the nonparametric test is to test whether there are significant differences between the price data of different airline ticket agencies. The main nonparametric test methods used in this paper include Kreskas-Wallis test and Wilcoxon signed rank test. In principle, Kreskas-Wallis test can explain whether there is a significant difference between multiple groups of data, but it is impossible to exclude the possibility that there is no difference between some groups of data in the 
multiple groups of data. Therefore, based on the Kreskas-Wallis test, we use Wilcoxon signed rank test to obtain more reliable conclusions. The above two nonparametric tests have the following assumptions: H0: there is no significant difference between the samples. [6].

Table 2. Wilcoxon signed rank test (first class)

\begin{tabular}{|c|c|c|c|c|}
\hline & $O T A_{1}$ & $O T A_{2}$ & $O T A_{3}$ & $O T A_{4}$ \\
\hline$O T A_{4}$ & - & $P<0.001$ & $P<0.001$ & $P<0.001$ \\
\hline$O T A_{2}$ & - & - & $P<0.01$ & $P<0.01$ \\
\hline$O T A_{3}$ & - & - & - & $P>0.1$ \\
\hline$O T A_{4}$ & - & - & - & - \\
\hline
\end{tabular}

Table 3. Wilcoxon signed rank test (economy class)

\begin{tabular}{|c|c|c|c|c|}
\hline & OTA $_{4}$ & OTA $_{2}$ & OTA $_{3}$ & OTA \\
\hline OTA $_{4}$ & - & $P<0.001$ & $P<0.001$ & $P<0.001$ \\
\hline OTA $_{2}$ & - & - & $P>0.1$ & $P>0.1$ \\
\hline OTA $_{3}$ & - & - & - & $P>0.1$ \\
\hline OTA & - & - & - & - \\
\hline
\end{tabular}

First, the test results of economy class data show that the P values of OTA1 and OTA2, OTA3 and OTA4 test results are less than 0.001 , indicating that there are significant differences between the prices of OTA 1 and OTA2, OTA3 and OTA4, and the values of OTA2 and OTA3, OTA3, and testing results are more than 0.1 , that is, they cannot be refused. The original hypothesis was that there was no significant difference between the three groups of data. [7] The above two conclusions can explain that the main reason for the significant difference in the economy class data of the four online ticket agencies is that the price difference between OTA1 and other three online ticket agencies is more obvious, while the price of the economy class of OTA2, OTA3 and OTA4 does not differ significantly. Secondly, the test results of the first class data show that there are significant price differences between OTA1 and OTA2, OTA1 and OTA3, OTA1 and OTA4, OTA2 and OTA3, OTA2 and OTA4, and there is no significant price difference between OTA3 and OTA4.[8]

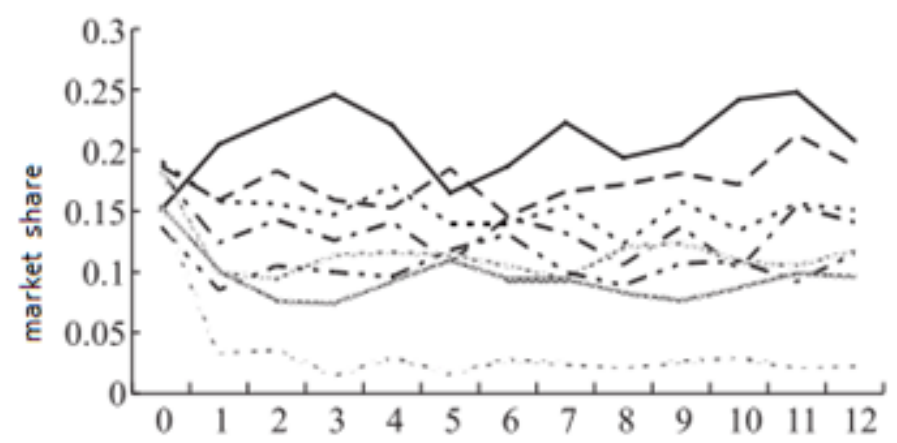

Fig 1. Market evolution status of tourist passenger with different ticket prices 


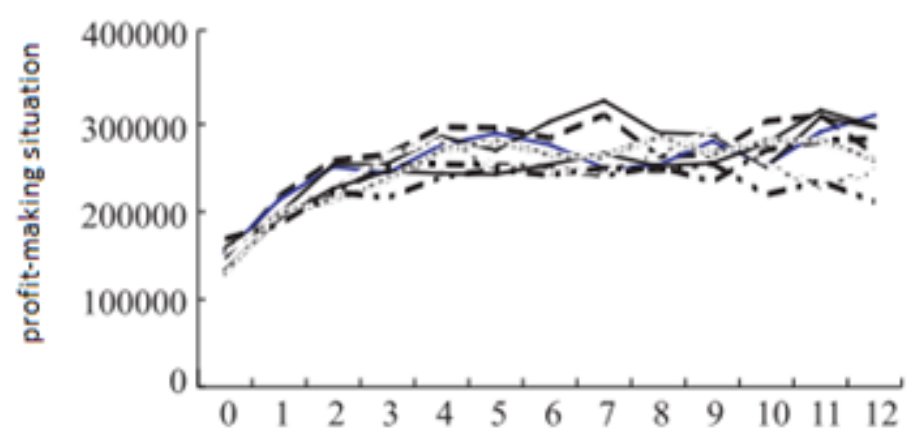

Fig 2. Payoff status of tourist passenger with different ticket prices

The introduction of e-commerce affects consumers as well as commodity suppliers. The impact on suppliers is not only the intensification of market competition, but also the rise of market share after the opening of e-commerce technology. And there was no marked increase in the price of fares. [9].

\section{Summary}

As a new research field with distinct problem oriented characteristics, the research of China civil aviation transportation industry in the future should adapt to the urgent demand of the rapid development of the civil aviation market and the globalization competition brought by the open sky trend. The study of the Chinese civil aviation market shows that there are still significant price differences in the same commodity under the environment of e-commerce. From a practical point of view, this study finds that the efficiency of the market transaction is the result of many factors, and the trade friction can be reduced but not completely eliminated; second, in the e-commerce market, Consumers' recognition ability decreases with the increase of the total information they receive, and the search fee may not rise or fall. [10]Therefore, guiding the healthy development of China's avionics business is the focus of future attention.

\section{References}

[1]. Brynjolsson E, Smith M. Frictionless commerce Comparison of internet and conventional retailers [J]. Manage-mint science, 2000, 46 (4): 563-585.

[2]. Lynch J G, Ariel Dewing online: search cost and competition on price, quality and distribution [J]. Marketing science, 2000, 19 (1): 83-103.

[3]. Brown J R, Goose Andes the internet make markets more competitive evidence from the life insurance industry [EB/OL]? [2015- 12- 21].http://www.nber.org/papers/w7996.

[4]. He L. Research on core competence strategy of China Southern Airlines [D]. Tianjin: College of Economic \& Management, Civil Aviation University of China, 2007.

[5]. GU Yuan Xian, Cheng Guangdong. Research and application of numerical methods for structural shape optimization design. Computational structural mechanics and its applications, 1993, 10 (3): $321 \sim 335$

[6]. Nero G, Black J A. Hub-and-spoke networks and the inclusion of environmental costs on airport pricing [J]. Transportation Research, Part D: Transport and Environment, 1998, 3(5): 275-296.

[7]. Stigler G Jute economics of information [J].Journal of pot-lyrical economy, 1961, 69 (3): 213 225.

[8]. Bakes J Reducing buyer search cost: implications for electronic marketplaces [J]. Management science, 1997, 43 (12): 1613-1630. 
[9]. LEE H God Electronic marketplaces lower the price of goods [J].Communication of the ACM, 1997, 41 (12): 73-80.

[10]. Bailey $\mathrm{J}$ Intermediation and electronic markets: aggregation and pricing in internet commerce [D]. Cambridge, MA: Massachusetts Institute of Technology, 1998. 